Article

\title{
Demand Side Management Effects on Substation Transformer Capacity Limits
}

\author{
Kerry D. McBee, Jacquelyn Chong and Prasanth Rudraraju * \\ Department of Electrical and Computer Engineering, California State University, Fresno, CA 93740, USA \\ * Correspondence: prasanthrudraraju@mail.fresnostate.edu
}

Received: 24 June 2019; Accepted: 7 August 2019; Published: 9 August 2019

check for updates

Featured Application: The research provides insight into the effects that high penetrations of photovoltaic (PV) systems, energy storage (ES) applications, and electric vehicle (EV) charging systems will have on substation transformer capacity ratings. The manuscript identifies how these applications change the operational conditions of a transformer to the point where capacity ratings (normal and emergency) should be adjusted to account for the additional internal heating in the windings and oil. The research also identifies how harmonic distortion induced by PV, ES, and EV charging equipment affects capacity ratings. The results of the analysis are utilized to describe mitigating approaches for existing units and new units being designed. The approaches are applied to the design attributes of a 50 MVA SPX Waukesha transformer.

\begin{abstract}
In high penetrations, demand side management (DMS) applications augment a substation power transformer's load profile, which can ultimately affect the unit's capacity limits. Energy storage (ES) applications reduce the evening peaking demand, while time-of-use rates incentivize end-users to charge electric vehicles overnight. The daily load profile is further augmented by high penetrations of photovoltaic (PV) systems, which reduce the midday demand. The resulting load profile exhibits a more flattened characteristic when compared to the historical cyclic profile. Although the initial impact of PV and ES applications may reduce a unit's peak demand, long-term system planning and emergency conditions may require operation near or above the nameplate rating. Researchers have already determined that a flattened load profile excessively ages a unit's dielectrics more rapidly. The focus of this research was to identify an approach for establishing new transformer capacity limits for units serving flattened load profiles with a high harmonic content. The analysis utilizes IEEE standards C57.91 and C57.110 to develop an aging model of a 50 MVA SPX Waukesha transformer. The results establish a guideline for determining transformer capacity limits for normal operation, long-term emergency operation, and short-term emergency operation when serving systems with high penetrations of DSM applications.
\end{abstract}

Keywords: demand side management; electric vehicles; energy storage; harmonic distortion; photovoltaic; power quality; power transformer; total harmonic distortion

\section{Introduction}

Substation planning is heavily reliant upon identifying the proper capacity for its transformers. Substation bus work and breaker equipment is designed to support the total specified MVA output as defined by the transformer capacity, which can vary from utility to utility depending upon operating conditions [1]. Increased implementation of demand side management (DSM) to control high penetrations of energy storage (ES) applications and electric vehicle (EV) charging can greatly affect the demand profile substation transformers typically experience. When the effects of EV charging 
and ES applications are combined with the output of photovoltaic (PV) systems, the existing capacity limits of installed substation transformers can be affected.

The nameplate rating of a transformer is based upon given criteria established by IEEE Std. C57.91-2011 [2]. The ratings are determined by identifying the MVA output (under specific operating conditions) that produces a specific transformer internal temperature, which dictates the normal and emergency capacity ratings of the unit [2]. Acceptable operating temperatures are established based upon safety limits for oil temperature and the location on the conductor windings that experience the highest temperature, which is commonly referred to as the hottest spot. Dielectric breakdown of the insulation occurs more rapidly at the hottest spot location. Transformer aging typically refers to the condition of the insulation at this winding location [2]. These standards, which measure hottest spot effects as a function of demand, allow utilities to compare the operation of units manufactured by different companies, who still must comply with the same rating standards [1].

The utilized capacity of a transformer, which may be different from the actual nameplate rating, is usually tied to the end of life of a given unit [1]. Utilities determine the units capacity limits by identifying the peak output that a unit can produce without severely reducing the amount of expected life, which is estimated at approximately 180,000 h or 25 years [2]. Many transformers in use today were designed or specified based upon a specific peak energy demand and load factor. As the penetration of distributed energy resources (DER) increases on the distribution system, utilities will seek to control their usage and output through DSM programs to optimize the operation of the grid, prolong the need for adding capacity, prevent the need to run less efficient peaking generators, and prolong the life of distribution and transmission equipment [3]. Unfortunately, in high penetrations these energy applications augment the load profile typically experienced by a substation transformer $[4,5]$.

The power industry paradigm that has been in existence for nearly a century is changing from one that leans heavily upon centrally owned power plants to one that consists of thousands of energy suppliers in the form of residential PV and ES systems. The increased number of sources, which are not directly controlled by utilities, introduce uncertainty in the stability of the system. To promote stability and increase overall system efficiency, utilities and government agencies implement numerous programs to indirectly control residential generation and energy usage. For cases where the penetration of customer participation is high, substation transformers may experience operating conditions sufficient to lower existing capacity limits [6]. Substation transformer derating due to a DSM program was first documented in the publication by Staats, which attempted to address transformer capacity derating due to high penetrations of electric vehicle (EV) charging [7].

High penetrations of PV systems, ES applications, and EV charging can severely modify the characteristics of a power transformer's daily load profile, which historically allowed for a cooling down period at some point during the day $[1,2,6,8]$. The new load profile, which is flatter than the historical profile, can possibly lead to increased operating temperatures given the same peak demand. The increased transformer temperatures can lead to higher than expected losses, aging, and damage when compared to the operation of a power transformers serving a historical cyclic load profile.

As the energy demand approaches the pre-established capacity limit of a transformer, internal operating temperatures increase at an exponential rate, which inherently increases the temperature at the hottest spot and thereby the aging of the transformer insulation [2]. As evident in Figure 1, which represents the aging of a $50 \mathrm{kVA}$ transformer unit as a function of per unit load, aging increases nonlinearly when the peak demand is greater than 0.95 per unit at rated ambient temperature. For a flattened load profile, which is considered abnormal by IEEE Std. 57.91, this excessive aging occurs for longer periods of time when compared to that of a traditional cyclic load profile [2]. For operations beyond the established capacity limit, sustained internal temperatures beyond recommended IEEE limits can result in equipment damage and/or catastrophic failure [2]. 


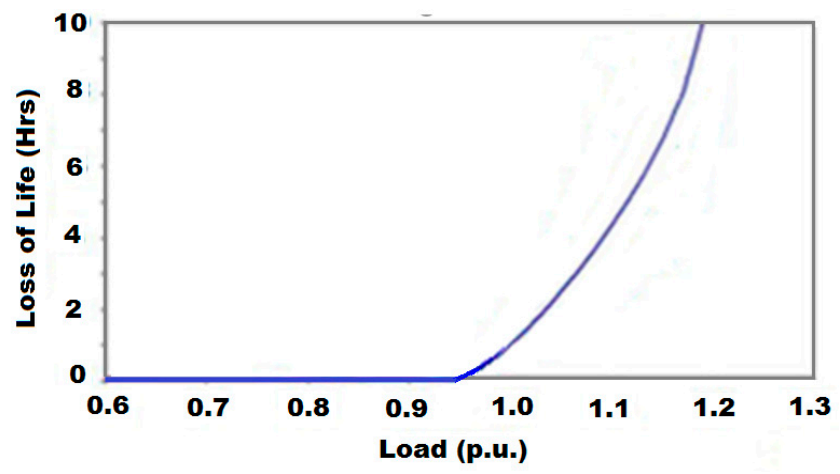

Figure 1. Paper insulation aging as a function of per unit load for a $50 \mathrm{kVA}$ liquid immersed transformer.

The research performed by McBee illustrated how a flattened load profile will increase the aging of a 50 MVA SPX Waukesha power transformer due to increased temperatures at the hottest spot [6]. The goal of the research was to determine if high penetrations of PV, ES applications, and EV charging would affect the aging of a typical substation transformer in the US. Utilizing the results from various research endeavors focusing on the grid impact of PV, ES applications, and EV charging, the authors established two test load profiles, one representing the historical load profile and a second representing the effects of high penetrations of PV, ES applications, and EV charging. Transformer aging due to both load profiles were analyzed and compared with the methods described IEEE Std. C57.91-2011 [2]. The analysis revealed that given the same peak demand, a flattened profile can age transformer insulation at a rate $50 \%$ greater than expected [6]. With aging identified previously, the author's goal for this manuscript is to determine how to mitigate the excessive aging induced by high penetrations of PV, ES applications, and EV charging.

Although the initial impact of increased penetration rates of renewable energy devices and ES applications may lower the peak energy demand on substation transformers, long-term system planning dictates that utility companies utilize substation transformer units to their full capacity $[1,9]$. Consider the long-term options when a substation unit fails on a system serving flattened load profiles. If ES applications have severely reduced the peak demand as compared to the historic demand, the utility would have no incentive to install a unit with the same peak capacity. The load is picked up indefinitely by a neighboring unit or the unit is replaced with a smaller and less expensive unit. From a power system planning perspective, there are still thousands of units in existence on the grid that should be utilized to their full potential [10-12]. Therefore, over time "underloaded" units would be phased out as the equipment fails or is upgraded.

Integration of PV, ES applications, and EV charging requires the implementation of power electronics, which increase the harmonic distortion on the grid. The heat generated from harmonic distortion also contributes to the internal heating of a transformer, which increases aging and can thereby impact capacity limits $[9,13,14]$. Although there are equipment standards that limit the amount of harmonic distortion induced by a single device, system values exceeding IEEE Std. 519-2014 harmonic voltage limits have been recorded on power systems even though the induced harmonic current levels are considered acceptable [15-18].

The goal of the described research is to develop an approach for establishing acceptable capacity limits or design requirements for units that serve a flattened load profile with a significant harmonic content. As with the research performed previously by the authors, a transformer aging model based upon IEEE Std. C57.91 and IEEE Std. C57.110 was utilized to identify load profile effects on internal temperatures and thereby capacity limits [6]. The derating and design parameter identification procedures were applied to the same $50 \mathrm{MVA}, 118 / 14.3 \mathrm{kV}, \mathrm{Z}=12 \%$, SPX Waukesha transformer utilized to establish excessive transformer aging due to a flattened profile [6]. The model was built utilizing data from the SPX manufactured test report. The analysis assumes the unit's solid dielectrics 
were comprised of thermally upgraded kraft (TUK) paper and the liquid dielectric consisted of mineral oil, both of which are considered industry standards.

\section{Load Profile Development}

Determining methods for evaluating transformer capacity is heavily reliant upon establishing operating conditions that reflect the (1) historical transformer load profiles and (2) the implementation of DSM programs applied to high penetrations of DER applications. The main difference in transformer capacity can be characterized by comparing the internal temperatures induced by the historical load profile to those produced by a profile flattened by high penetrations of PV, ES applications, and EV charging.

\subsection{Historical Profile vs. Flattened Profile}

The research performed previously by the authors established a (1) typical load profile and (2) a load profile that exhibits more flattened characteristics due to high penetrations of PV, ES applications, and EV charging [6]. These profiles are utilized in this research as Profile B (typical load profile) and Profile A (load profile with high penetrations of DER and DSM). The profiles were developed by combining field measurements and results from numerous research projects.

A typical substation transformer load profile (Profile B) was established from load profile descriptions given in Willis, examples provided in IEEE Std. C57.91-2011, and field measurements acquired in McBee, which also correspond to the results presented in research by Vasudevarao, Stifter, and Zehetbauer $[1,2,8,19]$. To evaluate the impact of high penetrations of $\mathrm{PV}$, load profile changes established in research performed by CalISO was applied to the typical load profile [5]. These results also aligned with profiles developed in research performed by Fezai and Belhadj [20]. To account for the impact of high penetrations of ES applications, the load profile changes established in Munson's research was applied to the typical profile [4]. These profile augmentations align with changes produced by hybrid PV and ES systems that are utilized to improve grid stability and customer participation [21-24]. Utilizing time-of-use practices by utility companies such as Pacific Gas \& Electric in California that incentivize customers to charge during the period between $11 \mathrm{pm}$ and $7 \mathrm{am}$, the impact of EV charging was applied to the typical load profile [25]. These load profile changes align with the predictions documented in research by Rezaee, Farjah, and Khorramdel [26]. The resulting load profile exhibits more flattened characteristics than the historical profile. Given the goal of DSM applications and the system impact of DER applications, these profile variations should be expected if penetrations are high.

The goal of DSM is to augment the energy demanded by customers so that it is economically and operationally efficient. With high penetrations of DER, including EVs operating as vehicle-to-grid (V2G) devices, the impact is sufficient to change the characteristics of a transformer's load profile [27-29]. Many utility companies utilize load profile characteristics to establish capacity ratings [1,2]. Therefore, changing a unit's load profile can inherently change its effective rating.

The penetration of ES applications is expected to continue to grow [27]. One of the main goals of applying ES applications is to diminish the need to operate less efficient "peaking" generators when customer demand is high. In high penetrations, this peak shaving application severely augments the historical load profile during the peaking period [1,28]. Most energy supplied to ES applications originates from PV systems, residential and utility owned. In high penetrations, PV systems will also augment the historical load profile $[3,4,28]$.

PV systems are becoming more popular as home builders and local governments drive to install more net zero homes [30-32]. Energy generation from PV systems is a function of sunlight, and therefore peak generation occurs from sunrise to sundown. In high penetrations, PV generation reduces the energy consumption during this period, which causes the $24 \mathrm{hr}$ load profile to resemble a "duck curve" [5]. Due to economics and system stability, some energy generated by PV systems is 
stored in ES applications and released during the peaking period. This application further flattens the load profiles experienced by substation transformers.

Due to the amount of energy required to charge EVs, many utilities utilize time-of-use rates to influence customers to charge their vehicles during off-peak hours, which occurs between the period of $11 \mathrm{pm}$ and 7 am [33,34]. This energy shift increases a power transformer's load profile during this period, which is historically low. As the penetration of EVs increase, it is expected that the nightly energy demand will continue to grow.

The combined effects from high penetrations of ES applications, PV systems, and nightly EV charging will make the historical load profile flatter. A load profile is quantified by the term "load factor" $(L F)$, which is measured by dividing average demand $\left(L_{A V G}\right)$ by the peak demand $\left(L_{P K}\right)$, as illustrated in (1). A typical historical load factor ranges between 0.50 and 0.75 . Increased penetration of ES applications, PV systems, and EV charging systems can result in LF values in excess of 0.80 . The new load profile, which reflects the effects of high penetrations of DSM and DER applications, is flatter, illustrated in Figure 2, and designated as Profile A in this research. To identify the appropriate capacity limit, the authors analyzed the effects of Profile A with varying peak energy demands (range: 75-1.20 per unit). Unlike the historical load profile, which is illustrated as Profile B in Figure 3, the $L F$ for the flattened profile ranges between 0.835 and 0.913 depending on peak demand.

$$
L F=\frac{L_{A V G}}{L_{P K}}
$$

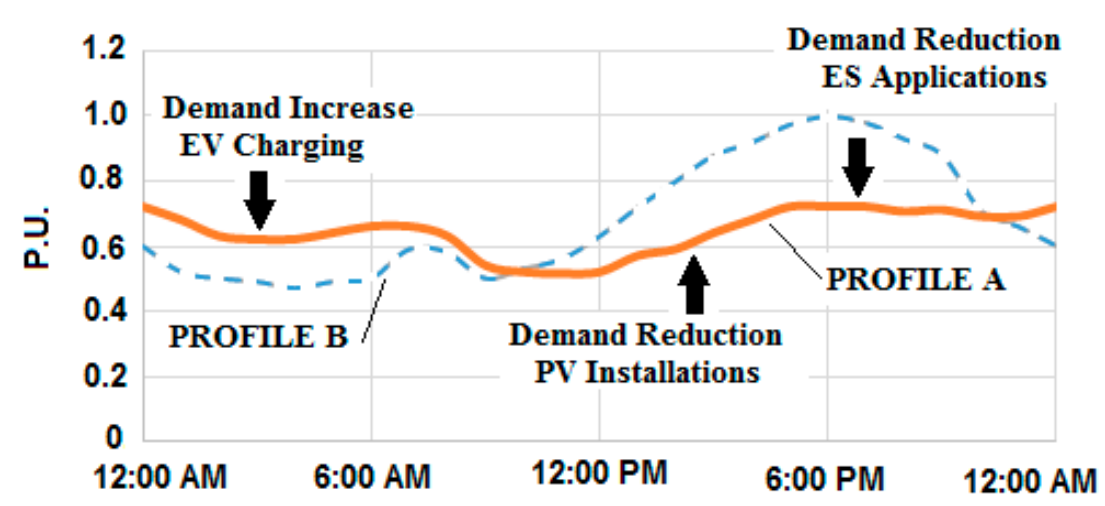

Figure 2. DER effects on historical load profile that result in a flattened load profile (Profile A).

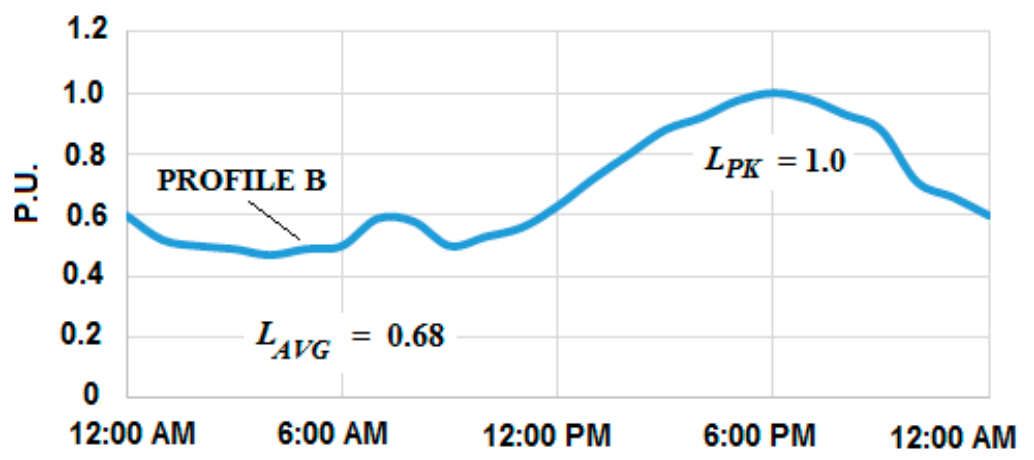

Figure 3. Historical cyclic load profile (Profile B) experienced by substation transformers.

The historical load profile utilized in the comparison analysis possessed the typical characteristics historically experienced by substation power transformers [1,2,7]. The period between 12am and 6am illustrates the lowest demand, while the peak demand occurs near $6 \mathrm{pm}$. The peak demand for the profile was varied for the analysis so that aging comparison could be performed for varying loads. As with peak load augmentations with Profile A, increases in demand were performed by equally 
increasing the energy demand for all hours. The load factor for the profile utilized for the analyses ranged between 0.65 and 0.78 depending upon energy peak (range: $0.90-1.50$ per unit).

\subsection{Harmonic Distortion Evaluation}

Derating distribution, industrial, or commercial transformers due to heating induced by harmonics distortion is a well-documented application [35-39]. As defined in Faiz, Ghazizadeh, and Oraee, the four methods applicable to derating transformers include IEEE recommendations, analytical methods, experimental approaches, and finite elements [14]. Depending upon the application, load type, and available transformer and system information, each approach possesses disadvantages and advantages. Within these classifications, researchers have developed numerous approaches for derating transformers serving nonlinear loads [40-43]. However, as defined by the research in Das and Radakovic, not all transformers serving nonlinear loads must be derated. Derating is dependent upon the transformer's top oil temperature rise (TOR), which is a function of ambient temperature, loading, solid and liquid dielectric properties, and transformer construction [9].

Historically, most system problems caused by harmonic distortion originate at a single source or customer, which prompts mitigation efforts to be directed exclusively at one location, bus, circuit, or subdistribution circuit. In fact, most research endeavors focus on derating transformers rated less than 2 MVA that serve mostly dedicated nonlinear loads [9,35-43]. For substation transformers that serve a combination of residential, industrial, and commercial loads, accounting for harmonic is typically ignored due to the low levels of distortion and isolation of problems [1]. As the penetration of nonlinear loads increase on the grid in the form of DER power electronics, computer supported equipment, and electronic devices, should harmonic distortion be accounted for in determining substation transformer capacity?

The heat generated by harmonic distortion—both current and voltage—can accelerate the aging of transformers depending upon it effects on TOR and the surrounding ambient temperatures $[9,13,17]$. The research performed previously by the authors identified additional heating as an effect of serving a flattened load profile due to high penetrations of PV, ES applications, and EV charging [6]. Therefore, combining the heat produced by nonlinear devices and the heat produced by a flattened load profile can accelerate insulation aging when compared to that induced by a historical demand.

DER applications, residential and utility owned, rely upon inverter based power electronics, which introduce harmonics onto the system they are connected with. The increased implementation of DER applications contribute to the existing levels of harmonic distortion, which is a result of consumer electronic devices, fluorescent lighting, high efficient appliances, and computers. Although several industry standards limit the amount of harmonic distortion produced by individual nonlinear devices (inverters, CFLs, etc.), the overall accumulation of distortion may still rise above acceptable limits listed in IEEE Std. 519-2014 [15-17,44,45]. Before one can determine how severe harmonic distortion will become due to high penetrations of DER devices, one must first answer the question: "What are the typical existing levels of harmonic distortion?"

To identify an existing harmonic distortion baseline for the transformer capacity analysis, the existing harmonic distortion on a $15 \mathrm{kV}$ distribution system located in an urban area ( $>750,000$ end-users) was evaluated by the authors. The results of the analysis are to be utilized to develop the appropriate harmonic spectrum for the transformer capacity analysis. The assessment included analyzing voltage and current harmonic distortion measurements acquired during 401 quality service investigations performed by the utility company at end-user service meters between 2009 and 2015. The assessments, which were performed on seventy-four different $13.2 \mathrm{kV}$ feeders, led to the identification of four substation power transformers that serve feeders possessing low $(<3 \%)$, medium $(3-5 \%)$, and high $(>5 \%)$ levels of voltage total harmonic distortion $\left(\mathrm{THD}_{\mathrm{V}}\right)$. Moving forward these transformers are referred to as XFMR 1, XFMR 2, XFMR 3, and XFMR 4.

Because transformer aging is a function of current harmonic distortion, the harmonic current spectrum of the load on each substation transformer was monitored for ten consecutive days. The 
results indicate that even at today's low levels of DER penetration, current total harmonic distortion $\left(\mathrm{THD}_{\mathrm{I}}\right)$ at substation transformers can fluctuate between 3 and $9 \%$ during peak load conditions even if $\mathrm{THD}_{\mathrm{V}}$ is below the IEEE Std. 519 limit of $5 \%$ [15]. These results suggest that increased penetrations of PV, ES applications, and EV charging may easily push the average $\mathrm{THD}_{\mathrm{I}}$ above $10 \%$. Tables 1 and 2 list the results of the substation transformer monitoring analysis. Figure 4 illustrates the harmonic spectrum of XFMR 4.

For the capacity limit analysis of the 50 MVA SPX transformer, the harmonic distortion was varied throughout the $24 \mathrm{~h}$ period to mimic the typical distortion experienced by the evaluated units. The distortion consisted of the $3 \mathrm{rd}, 5 \mathrm{th}$, and 7 th harmonic frequencies and matched the harmonic composite illustrated on XFMR 4. As THD I increased between 0 and 35\%, the contributions of the $3 \mathrm{rd}$, 5th, and 7th harmonics were increased equally to maintain the percent contributions. For example, at $4 \mathrm{am}$ the contribution from the 3rd harmonic distortion is always 3.75 times greater than the contribution from the 5 th harmonic distortion.

Table 1. Harmonic voltage monitoring results.

\begin{tabular}{cccc}
\hline Substation Transformer & Average THDV (\%) & Peak THD $_{\mathbf{V}}$ (\%) & $\begin{array}{c}\text { Average THDV during } \\
\text { Peak Load (\%) }\end{array}$ \\
\hline XFMR 1 & 1.62 & 2.76 & 1.46 \\
XFMR 2 & 4.53 & 5.52 & 4.40 \\
XFMR 3 & 4.89 & 5.23 & 4.76 \\
XFMR 4 & 5.33 & 7.84 & 4.83 \\
\hline
\end{tabular}

Table 2. Harmonic current monitoring results.

\begin{tabular}{cccc}
\hline Substation Transformer & Average THD $\mathbf{\text { ( \%) }}$ & Peak THD $_{\text {I }}$ \%) & $\begin{array}{c}\text { Average THD Iuring } \\
\text { Peak Load (\%) }\end{array}$ \\
\hline XFMR 1 & 2.68 & 4.38 & 2.78 \\
XFMR 2 & 10.17 & 15.79 & 9.18 \\
XFMR 3 & 6.74 & 8.49 & 6.01 \\
XFMR 4 & 10.45 & 15.13 & 7.67 \\
\hline
\end{tabular}

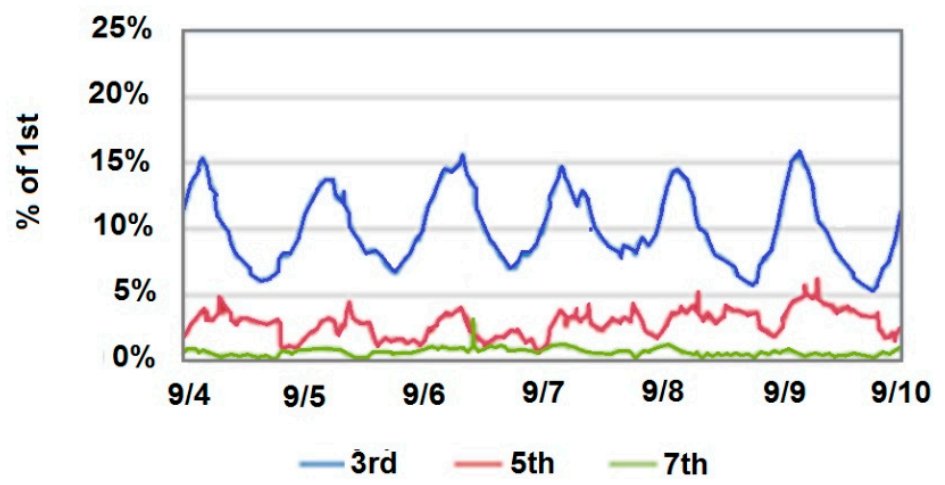

Figure 4. Current harmonic spectrum for XFMR 4.

\subsection{Transformer Thermal/Aging Model Description}

A transformer model based upon the IEEE Std. C57.91-2011 transient model (Annex G) was evaluated to assess how a transformer's solid dielectric (paper insulation) is aged by Load Profiles $A$ and $B$ with varying levels of harmonic distortion. Most substation transformers are balanced so that the voltage between phases does exceed a 3\% difference. With smart grid monitoring and switching capabilities, ensuring system balance between phases is achieved easier when compared to past systems. The transformer model applied in the research assumes the substation transformer serves a balanced load, which nullifies the disadvantage of applying the IEEE method for derating [14]. 
Analysis of this model with varying load profiles identifies the peak demand that produces internal transformer temperatures that meet the limits set forth by IEEE Std. C57.91-2011 for normal and emergency capacity limits.

In accordance with IEEE Std. C57.91-2011, this paper refers to transformer aging as the mechanical degradation of a unit's solid dielectric by means of thermal stress that is generated from the current flowing through the windings and leads [2]. Reducing the tensile and dielectric strengths of insulation reduces the material's ability to withstand short circuit stress and the associated mechanical movement, which increases the possibility of a failure during a downstream fault event. The models utilized in the analyses assume the transformer overall dielectric protection consists of TUK paper insulation submerged in mineral oil, which is consider the industry standard [2].

The IEEE Std. C57.91-2011 transient model calculates temperature of the transformer winding hottest spot, which is the area that experiences the most paper insulation aging and is considered the "weak link" of the unit regarding potential failure. The model calculates internal temperature variations in 30-second increments utilizing demand, ambient temperature, cooling system, winding properties, altitude, tap position, tank configuration, rated losses, and oil properties [2]. Because the research goal was to identify how a flattened load profile with a high harmonic content affects transformer temperatures, derating factors such as altitude adjustment and tap position were ignored so that a true measurement of the load profile effects could be identified. Unfortunately, the IEEE Std. C57.91-2011 model does not account for harmonic distortion, which is known to create additional internal heating [13]. To account for harmonics, the harmonic loss factors described in IEEE Std. C57.110-2008 were applied to the IEEE Std. 57.91-2011 transient model [13].

IEEE Std. 57.91-2011 categorizes transformer losses into three categories: (1) no-load losses (excitation losses), (2) load losses (impedance losses), and (3) total losses (sum of no-load losses and load losses) [10]. Load losses are comprised of $I^{2} R$ losses and "stray losses", which are determined by subtracting $I^{2} R$ losses from the measured load losses during testing. Stray losses are comprised of winding losses (conductor strand eddy current losses and circulating current between strands) and component losses (core, core clamps, magnetic shields, and tank).

Testing has proven that winding losses $(\mathrm{Pec})$ tend to be proportional to the square of the load current and approximately proportional to the square of the frequency [13]. In short, the heat generated in the windings by harmonic current increases at a rate that is the square of the harmonic frequency $(h)$. This is one of the reasons harmonics can rapidly age transformers.

Because other stray losses are manifested within the core, clamps, and other structural components, the losses do not increase at a rate equivalent to winding losses. IEEE Std. C57.110-2008 recommends a conservative exponent factor of 0.8 instead of the square of the harmonic frequency $(h)$. Therefore, to account for harmonics in the IEEE Std. C57.91-2011 transformer model, a harmonic loss factor $\left(F_{H L}\right)$ and a harmonic loss factor for other stray losses $\left(F_{H L-S T R}\right)$ were applied to winding losses and other stray losses within the transformer model. Equations (2) and (3) illustrate each of the loss factors, where $h_{\text {max }}$ represents the maximum number of harmonic frequencies present in the spectrum, $I_{h}$ represents the $r m s$ current at the $h$ harmonic frequency, and $I_{1}$ represents the $r m s$ fundamental current.

$$
\begin{gathered}
F_{H L-S T R}=\frac{\sum_{h=1}^{h_{\max }}\left[\frac{I_{h}}{I_{1}}\right]^{2} h^{0.8}}{\sum_{h=1}^{h_{\max }}\left[\frac{I_{h}}{I_{1}}\right]^{2}} \\
F_{H L}=\frac{\sum_{h=1}^{h_{\max }\left[\frac{I_{h}}{I_{1}}\right]^{2} h^{2}}}{\sum_{h=1}^{h_{\max }}\left[\frac{I_{h}}{I_{1}}\right]^{2}}
\end{gathered}
$$




\section{Capacity Rating Procedure}

Capacity limits are applied to existing transformer units to prevent excessive aging and/or long-term equipment damage. For transformers being designed, capacity limits are utilized for identifying the required design parameters. The following sections describe procedures for derating the capacity limits (normal operations and emergency) of an installed unit that is impacted by a flattened load profile with high harmonic content. Also provided are design specification recommendations for new units to mitigate the effects of increased operating temperatures due to a flattened profile. Each section describes the necessary procedures and then applies them to the 50 MVA SPX transformer model to provide an example.

The authors do not assume that all transformers are represented by the 50 MVA SPX unit. However, the analysis results are sufficient to provide insight into operating conditions that warrant additional engineering analysis based upon actual equipment attributes, existing capacity limits, and significant changes in the demand load profile.

\subsection{Existing Unit Derating—Normal Operations}

The goal of establishing a normal operation capacity limit is to ensure a transformer will deliver power effectively for its entire life expectancy, which is defined by IEEE Std. C57.91-2011 as approximately 180,000 $\mathrm{h}$ at full nameplate rating or 25 years given off-peak periods [2]. Given the same peak demand, a transformer serving Profile A (flattened profile) experiences higher internal temperatures for longer periods of time when compared to the effects of Profile B [6]. Units that are currently installed on the grid were sized utilizing the typical historical cyclic load profile. Therefore, it may be unlikely that the unit can deliver the same amount of peak demand without experiencing higher than expected internal temperatures and ergo increased loss of life. The best approach for preventing excessive aging of a unit is to derate the existing capacity limits [35-43]. Derating is established by reducing the peak energy demand of the unit to a level that maintains the hottest spot temperature $\left(\Theta_{\mathrm{H}}\right)$ below acceptable levels according to IEEE Std. C57.91-2011 [2].

Aging is affected by the ambient temperature surrounding the transformer unit; therefore, varying weather conditions throughout the year may dictate seasonal capacity limits [14]. If a single limit is satisfactory, analysis is performed to identify the time of year when daily average ambient temperatures and load requirements produce the most extreme transformer aging and/or internal temperatures.

Derating the capacity limits for normal operating conditions consists of identifying a multiplier that represents a "per unit" reduction in the existing acceptable peak demand, which could equal the nameplate rating of the unit. A peak demand derating multiplier is identified by comparing the original transformer aging $\left[A_{O}\right]$ to the new transformer aging $\left[A_{N}\right]$ induced by a flattened load profile. With all environmental conditions the same (weather, season, etc.), the only variance between existing $A_{O}$ and $A_{N}$ is the load factor, harmonic demand, and peak demand. The original aging $\left(A_{O}\right)$ is a function of the original load factor $\left(l_{O}\right)$, harmonic demand $\left(h_{O}\right)$, and peak demand $\left(c_{O}\right)$. Aging $\left(A_{N}\right)$ due to the new load requirements is a function of the new load factor $\left(l_{N}\right)$, harmonic demand $\left(h_{N}\right)$, and peak demand $\left(c_{N}\right)$. New aging should be equal to or less than the original aging $\left(A_{O}\right)$, which is illustrated in (4). The aging can be for a $24 \mathrm{~h}$ period, 1 week, or a month depending upon the desires of the utility.

$$
A_{O}\left(l_{O}, h_{O}, c_{O}\right)-A_{N}\left(l_{N}, h_{N}, c_{N},\right) \geq 0
$$

The dielectric insulation aging methods described previously were applied to the 50 MVA SPX test unit to identify aging associated with Profiles $\mathrm{A}\left(A_{N}\right)$ and $\mathrm{B}\left(A_{O}\right)$. Although variations in the new load factor $\left(l_{N}\right)$ and new harmonic distortion levels $\left(h_{N}\right)$ may not be controlled by the utility, the new peak demand $c_{N}$ can be controlled by establishing operational capacity limits.

Applying the procedure to the 50 MVA SPX test unit results in the following; for the SPX test unit to age at a rate equivalent to the one induced by Profile $\mathrm{B}\left(A_{O}\right)$ with a peak demand equal to 1.0 per unit, the peak demand of Profile A must be limited to 0.72 per unit. At this peak, the new load 
factor for the transformer demand is 0.881 , which is much higher than Profile B at $L F=0.682$. Table 3 summarizes the results of applying both Profiles. Figure 5 illustrates a comparison between Profile B with 1.0 per unit peak demand and Profile A with varying peak demands ranging between $0.70-1.2$ per unit. The figure utilizes the aging associated with Profile B as the benchmark for aging that all other conditions are compared with. For instance, a transformer experiencing a daily load profile similar to Profile A with a peak demand of 1.0 per unit and $\mathrm{THD}_{\mathrm{I}}=10 \%$ would age 2.10 times greater than a unit serving Profile $\mathrm{B}$ with a 1.0 peak demand and $\mathrm{THD}_{\mathrm{I}}=0 \%$. Table 3 summarizes the derating analysis.

Table 3. Capacity Rating (\% Nameplate) for Profile A \& B.

\begin{tabular}{ccc}
\hline Profile & A & B \\
\hline Load Factor & 0.881 & 0.682 \\
Capacity Limit & 0.72 per unit & 1.0 per unit \\
\hline
\end{tabular}

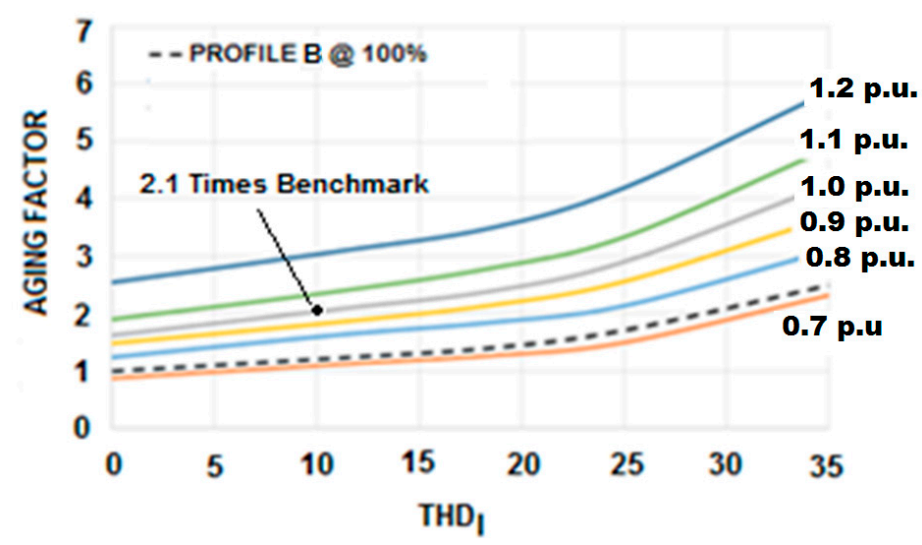

Figure 5. Comparison of aging induced by Profile B with peak energy demand $=1.0$ per unit and Profile A with energy demand ranging between 0.7 and 1.2 per unit.

\subsection{New Unit Design Changes-Normal Operations}

Utilities frequently provide design specifications to transformer manufacturers for large units designated for utilization in power substations. Adjusting design requirements can negate the long-term aging effects induced by Profile A with high harmonic content. Design changes to minimize aging due to Profile A must focus on minimizing the internal heat produced by a unit through normal operation.

The aging model defined in the previous section relies upon calculating internal temperatures of the unit, which is a function of ambient temperatures, energy demand, unit efficiency (losses: winding, core, and stray), thermal dielectric properties, cooling system, and tank construction [2]. The aging model converts the transformer electrical and physical components into a thermal circuit that is utilized to evaluate how rapidly heat due to current flow is dissipated through the windings, paper insulation, oil, and physical components of the tank. The complete thermal circuit consists of deriving the solution to thirty seven separate equations that represent temperatures at multiple internal locations of the transformer.

The goal of the thermal is circuit to calculate the transformer's winding hottest spot temperature $\left(\Theta_{H}\right)$, which is considered the location most susceptible to insulation failure due to heat. The thermal circuit determines the temperature of the unit's hottest spot for a given evaluation period $(\Delta t=0.5 \mathrm{~min})$ by calculating winding temperature based upon current flow, unit construction, and oil temperatures within the tank (top and bottom). The calculations also account for ambient temperature, rated ambient temperature, and the applied cooling system affects. The magnitude of $\Theta_{H}$ is applied to (5), which calculates the per unit transformer insulation aging $\left(F_{A A}\right)$ for $\Delta t$. To determine the equivalent aging 
$\left(F_{E Q A}\right)$ for a $24 \mathrm{~h}$ period, the calculated aging for each $\Delta t$ is summed and normalized by the total time, as illustrated in (6), where $N$ represents the total number of evaluation periods.

$$
\begin{gathered}
F_{A A}=e^{\left[\frac{15000}{383}-\frac{15000}{\Theta_{H^{-273}}}\right]} \\
F_{E Q A}=\frac{\sum_{n=1}^{N} F_{A A, n} \Delta t}{\sum_{n=1}^{N} \Delta t}
\end{gathered}
$$

To identify which design attributes possess the most impact in reducing aging due to a flattened load profile, the authors applied Profile A with a 1.0 per unit peak demand to the SPX 50 MVA unit while varying the design attributes listed below by percentages $(90 \%, 80 \%, 70 \%$, etc.) of their original design. Without any design changes, the accrued aging for a $24 \mathrm{~h}$ period was calculated at $37.43 \mathrm{~h}$ by (5) and (6). Figure 6 illustrates the aging for a $24 \mathrm{~h}$ period if each design attribute is varied exclusively.

- Stray Losses (construction variation)

- $\quad I^{2} R$ Losses (winding conductor variation)

- Core Losses (core construction variation)

- Hottest spot rise over ambient temperature (solid dielectric variation)

- Average winding temperature rise over ambient (solid dielectric variation)

- $\quad$ Litres/US gallons of fluid (tank size variation)

Design changes that impacted internal operating temperatures the most were (1) reducing the rated hottest spot rise over ambient (HRA) temperature and (2) minimizing the amount of heat produced by stray and $I^{2} R$ losses. Figure 6 illustrates transformer aging as calculated by (5) and (6) for each attribute as a function of original design variation in size or quantity (20-200\%).

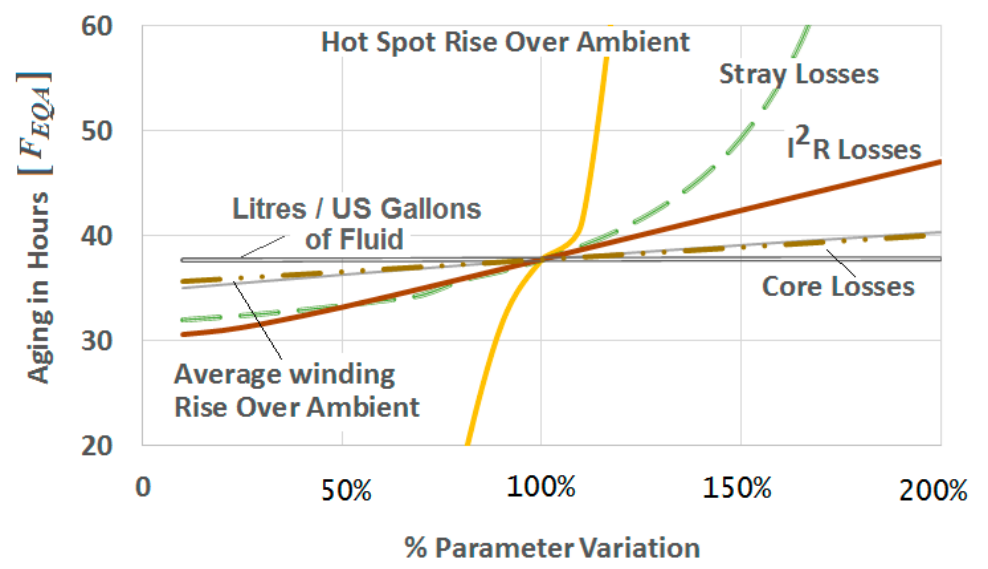

Figure 6. Aging induced by Profile A on the 50 MVA SPX unit as a function of design attributes.

HRA has a significant impact upon solid insulation aging. With $10 \%$ and $20 \%$ reductions in this value, the aging, as identified by (6), is reduced by $15.44 \%$ and $41.33 \%$ for the 50 MVA unit when Profile A is applied. Quantifying the trend line of (6) as a function of HRA as illustrated in Figure 6 results in the polynomial illustrated in (7), where $p_{h}$ is the percentage variation of HRA. To calculate the percent decrease in aging as compared to the existing HRA design value with Profile B ( $p_{h}=1.0$ per unit), (8) is applied to identify the aging reduction $R\left(p_{h}\right)$ as a function of HRA variation.

$$
\begin{gathered}
F_{E Q A}\left(p_{h}\right)=11204 p_{h}{ }^{4}-47040 p_{h}{ }^{3}-64558 p_{h}{ }^{2}+26747 p_{h}-4493 \\
R\left(p_{h}\right)=\frac{F_{E Q A(1.0)}-F_{E Q A\left(p_{h}\right)}}{F_{E Q A(1.0)}} \times 100 \%
\end{gathered}
$$


As defined IEEE Std. C57.91-2011, HRA is a function of the load current, the temperature rise of fluid at the top of the duct over bottom fluid, and the bottom fluid rise over ambient temperature. Improving the thermal insulation properties of the transformer would reduce these internal operating temperatures. Thermal properties are improved by reducing the thermal conductivity of the unit's liquid and solid dielectrics. The two most common types of solid dielectrics (paper insulation) for liquid immersed transformers are TUK and variations of Dupont's Nomex (910 or 410), which are documented as having at least $10^{\circ} \mathrm{C}$ better thermal performance than the former [46-49].

Nomex, which is classified as a high temperature dielectric, has historically been utilized in mobile transformers due to its light weight and strong thermal properties. However, in recent years utilities have begun applying the solid dielectric to substation units to improve thermal performance.

Utilizing Nomex can increase a unit's thermal rating, which allows for the winding hottest spot temperature to exceed $110{ }^{\circ} \mathrm{C}$ without considerable aging [49]. Because the cost of Nomex can be twenty times greater than TUK, completely upgrading the unit's solid dielectric may be infeasible. However, a hybrid insulation system composed of both TUK and Nomex may be sufficient to increase the thermal rating and regulate costs [49].

Utilizing alternative liquid dielectrics instead of mineral oil can also negate the additional heating effects, which essentially reduces the standard HRA. Since 2016, many researchers have identified better thermal performance utilizing mineral oil alternatives, such as natural ester and silicon $[49,50]$. The typical thermal class of TUK is $105^{\circ} \mathrm{C}$ in mineral oil. Based upon IEEE C57.154-2012, Nomex 910 has a thermal rating of $130^{\circ} \mathrm{C}$ in mineral oil and $140{ }^{\circ} \mathrm{C}$ in natural ester.

For older units that were designed with higher safety margins, improving HRA during a rewind might be accomplished by improving the amount and type of paper insulation. For newer units with smaller design safety margins, improving HRA during a rewind may be impossible due to the limited space and already the possible application of high temperature dielectrics.

Reducing losses ( $I^{2} R$ and stray) also contributes to mitigating the aging effects induced by Profile A. Losses manifest as heat within the conductor windings, which thereby increases the hottest spot temperature and ergo aging. The generated heat is absorbed by the bulk oil in the tank and radiator and eventually transferred through conduction to the external environment.

Stray losses are due to stray electromagnetic flux in the core, core clamps, windings, magnetic shields, and enclosure or tank walls. Therefore, reducing stray losses consists of minimizing the flux flowing through these components. If the original transformer unit design was created to produce minimal stray losses, increasing aging through these means may be impossible.

The loss of life characteristics of the 50 MVA unit when Profile A is applied is defined by (9), which quantifies the trend line of calculating (6) as a function of stray losses $\left(p_{s}\right)$ of the existing design. Equation (10) defines the percentage overall loss of life reduction as a function of the original design's $p_{S}$.

$$
\begin{gathered}
F_{E Q A}\left(p_{S}\right)=25 p_{S}^{6}-111 p_{S}{ }^{5}-190 p_{S}{ }^{4}-155 p_{S}{ }^{3}-66 p_{S}{ }^{2}-10 p_{S}+33 \\
R\left(p_{S}\right)=\frac{F_{E Q A(1.0)}-F_{E Q A\left(p_{S}\right)}}{F_{E Q A(1.0)}} \times 100 \%
\end{gathered}
$$

Increasing winding conductor size is a means of reducing $I^{2} R$ losses. Temperature of the conductor increases as more current flows through it. The conductor heat is emitted through the insulation and into the transformer oil through conduction. Increasing the cross-sectional area of the conductor reduces the total resistance of the winding and allows the same current to flow through the conductor at a lower temperature. The loss of life characteristics of the 50 MVA unit when Profile A is applied is defined by (11), which quantifies the trend line of calculating (6) as a function of the original design's winding resistance $\left(p_{I}\right)$. Equation (12) defines the overall aging reduction as a function of the original design's $p_{I}$.

$$
F_{E Q A}\left(p_{I}\right)=-0.86 p_{I}^{5}+5.4 p_{I}^{4}-13 p_{I}^{3}-15 p_{I}^{2}-0.6 p_{I}+33
$$




$$
R\left(p_{I}\right)=\frac{F_{E Q A(1.0)}-F_{E Q A\left(p_{I}\right)}}{F_{E Q A(1.0)}} \times 100 \%
$$

Increasing the winding diameter on new units is accomplished by sizing conductors based upon a higher ampacity. Unfortunately, increasing the winding on units being rewound may be impossible due to space limitations within the unit. Older units designed with higher safety margins might be easily upgraded with larger windings. Newer units designed for efficiency may not possess the additional space.

Transformer design attributes that have little effect on mitigating excessive aging due to a flattened profile include, increased volume of oil, increased tank volume, and decreased core losses.

\subsection{Derating_LLong-Term Emergency Rating}

Long-term emergency loading is defined by IEEE Std. C57.91-2011 as a condition where a transformer must regularly support energy demands greater than its nameplate capacity ratings, which forces the winding hottest spot temperature to climb above the acceptable temperature of $130{ }^{\circ} \mathrm{C}$ These conditions are rare and are typically caused by failures occurring on others sections of the grid that require repair lead times consisting of weeks. The two most important factors when determining capacity limit loading are the (1) reduced lifespan of the unit and/or the (2) long-term physical damage to the unit and/or oil.

In regards to aging, the approach defined in Section 3.1 is applicable to identifying acceptable loading limits. However, unlike application to normal operating conditions, the value of (4) will always be less than zero. The unit's owner should identify a new acceptable aging $\left(A_{E}\right)$ value that represents potential dielectric damage that impacts the long-term investment. Recall that this determination is to support an abnormal loading condition, therefore higher than normal aging is expected. The new evaluation equation is illustrated in (13).

$$
A_{O}\left(l_{O}, h_{O}, c_{O},\right)-A_{N}\left(l_{N}, h_{N}, c_{N},\right) \geq-A_{E}
$$

Prevention of long-term equipment damage may be the most important aspect of determining an acceptable capacity rating for a unit under these conditions. IEEE identifies controlling winding hottest spot temperature and oil temperature as keys to preventing damage to the unit [2]. To prevent damage and/or catastrophic failure, IEEE limits the hottest spot temperature to $140{ }^{\circ} \mathrm{C}$ and the top-oil temperature to $110^{\circ} \mathrm{C}$. Due to the constant load above its nameplate rating, both hottest spot temperature and top-oil temperature have higher values given the same peak demands.

Consider the 50 MVA SPX unit identified as the test unit for the analysis. If the unit serves the historical load profile (Profile B characteristics) with a peak demand ranging between 1.0 and 1.5 per unit, the metallic hottest spot temperature will reach a maximum value between $108^{\circ} \mathrm{C}-150{ }^{\circ} \mathrm{C}$ depending upon $\mathrm{THD}_{\mathrm{I}}$. With IEEE recommending a maximum value of $140^{\circ} \mathrm{C}$ the maximum peak demand this unit can serve the cyclic load with a $\mathrm{THD}_{\mathrm{I}}=10 \%$ is 1.47 per unit. Figure 7 a illustrates the hottest spot temperatures induced by Profile B with peak demands varying between 1.0 and 1.5 per unit.

Applying the same analysis with the flattened load profile (Profile A) revealed much higher temperatures. The transformer reaches $140{ }^{\circ} \mathrm{C}$ at a $\mathrm{THD}_{\mathrm{I}}=10 \%$ for a peak demand equal to 1.18 per unit, which is $80.27 \%$ of the peak energy demand when Profile B is served. Figure $7 \mathrm{~b}$ illustrates the hottest spot winding temperatures induced by Profile A for a peak demand ranging between 1.10 and 1.45 per unit. 


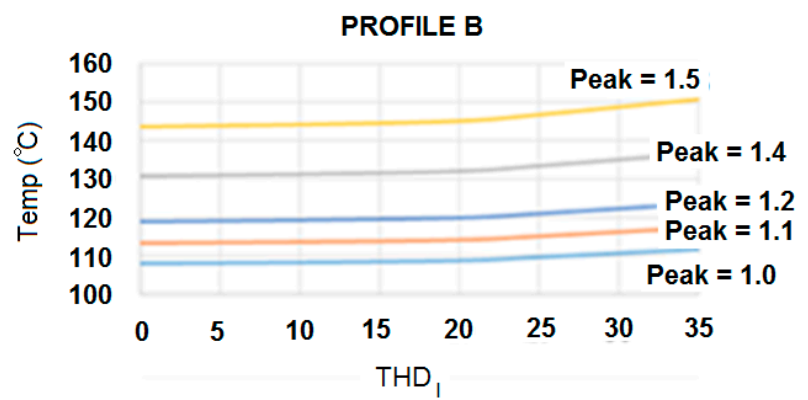

(a)

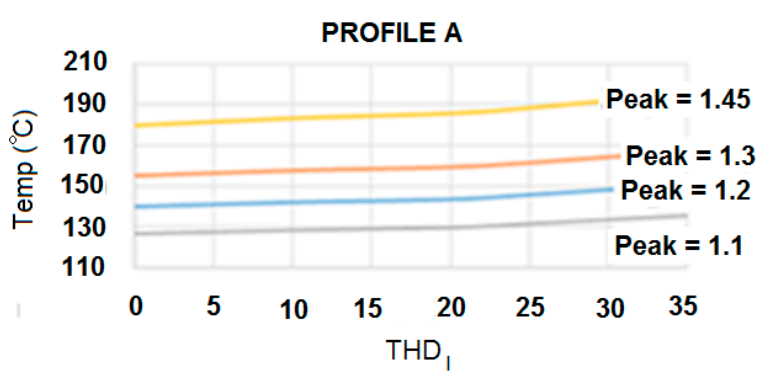

(b)

Figure 7. (a) Winding hottest spot temperatures induced by Profile B as a function of peak demand and harmonic current distortion. (b) Winding hottest spot temperatures induced by Profile A as a function of peak demand and harmonic current distortion.

The top-oil temperature analysis reveals very similar results. IEEE limits the top-oil temperature to $110{ }^{\circ} \mathrm{C}$ [2]. The test unit reaches the IEEE limit when serving 1.46 per unit and $\mathrm{THD}_{\mathrm{I}}=10 \%$ when serving demands with Profile B characteristics. When the flatter Profile A is applied to the unit, the IEEE limit is achieved when the peak demand reaches 1.20 per unit with $\mathrm{THD}_{\mathrm{I}}=10 \%$. Figure 8 illustrates the top-oil temperature of the 50 MVA unit as a function of peak demand, load profile type, and $\mathrm{THD}_{\mathrm{I}}$. One significant difference between applications of the two separate load profiles is the effects that harmonic distortion has on increased temperature for $\mathrm{THD}_{\mathrm{I}}$ values less than $20 \%$.

For the 50 MVA test unit, harmonic distortion has a significant effect on the top-oil temperature. When serving Profile B, the top-oil temperature increases at a rate of 0.10 degrees per percentage change in $\mathrm{THD}_{\mathrm{I}}$. However, when serving Profile A, the top-oil temperature increases at a rate of 0.35 degrees per percentage change in $\mathrm{THD}_{\mathrm{I}}$. These results suggest that utilities cannot ignore harmonic distortion if the demand exhibits characteristics similar to Profile A and the distortion is at least $10 \%$. The analysis also revealed that increased $\mathrm{THD}_{\mathrm{I}}$ has little effect on winding hottest spot temperature, which is evidence by rates of 0.05 and 0.15 degrees per percentage change in $T H D_{I}$ for Profiles $B$ and $A$. 

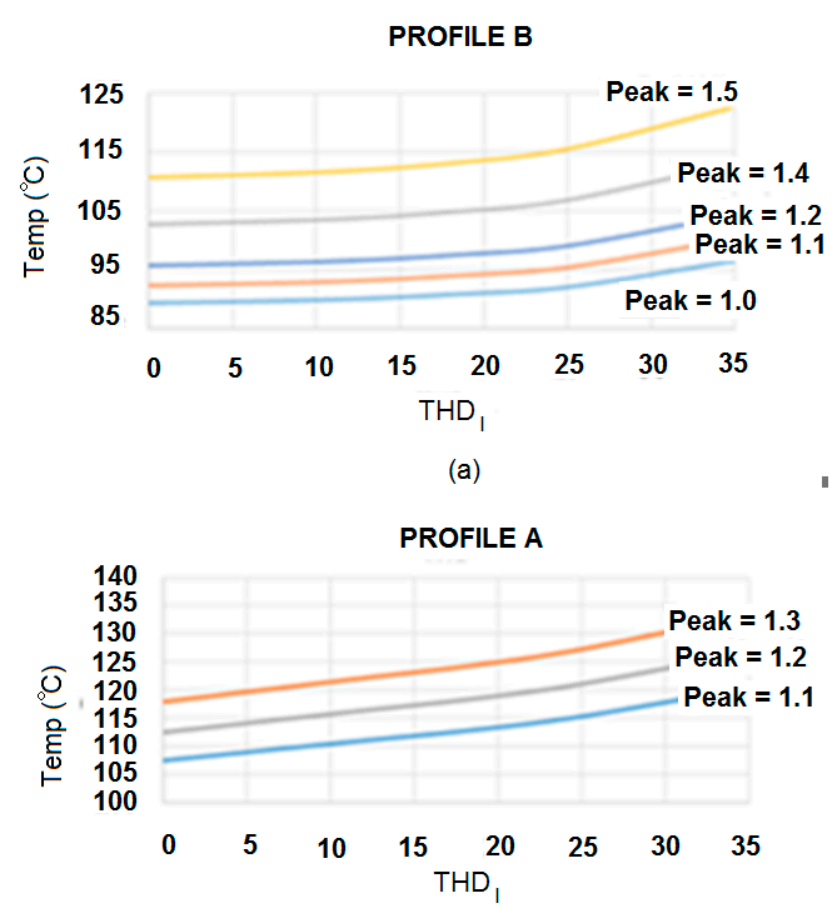

(b)

Figure 8. (a) Top-oil temperatures induced by Profile B as a function of peak demand and harmonic current distortion. (b) Top-oil temperatures induced by Profile A as a function of peak demand and harmonic current distortion.

\subsection{Derating-Short-Term Emergency Rating}

Short-term emergency ratings are established utilizing methods described in the previous section, with the exception that transformer damage is only considered and the conductor winding hottest spot temperature is increased from $140{ }^{\circ} \mathrm{C}$ to $180^{\circ} \mathrm{C}$ in accordance to IEEE [2]. Ultimately, the limiting attribute may be the top-oil temperature limit, which remains at $110{ }^{\circ} \mathrm{C}$ for this condition analysis due to the thermal limitations of mineral oil. Of course these limits do not account for gassing that may occur within the unit's tank during these conditions, which limit performance and life.

Short-term emergency loading is defined as the condition where a transformer must serve an energy demand that causes hottest spot temperatures in excess of $140{ }^{\circ} \mathrm{C}$ for a period of several hours. These are typically caused by failures resulting in second or third restoration contingencies on the system. Over the life of a transformer it should only experience one or two occurrences of these emergency conditions [2].

Applying the IEEE limitations for Profile $\mathrm{B}$ at a $\mathrm{THD}_{\mathrm{I}}=10 \%$ results in a capacity rating of 1.67 per unit (hottest spot temperature limit) and 1.46 per unit for top-oil temperature, which is the same limit identified during long-term emergency loading. Ultimately, the top-oil limitation dictates the rating of the unit at $46 \%$ above nameplate capacity.

To serve a load with Profile A characteristics, the short-term emergency capacity rating is 1.43 per unit and once again 1.20 per unit due to top-oil temperature. As with Profile B loading, the top-oil temperature dictates the ultimate capacity rating of the unit, which is only $20 \%$ above nameplate capacity.

\subsection{Overall Ratings for Test Unit}

Table 4 summarizes the capacity limits associated with normal operation, long-term emergency loadings, and short-term emergency loading for the 50 SPX Waukesha unit. Due to the flattened load profile, all capacity ratings based upon IEEE recommended operational limits for a liquid immersed 
transformer were reduced by a minimum of $85 \%$. Normal Operations possessed the largest derating requirement at $72 \%$.

Table 4. Summary of Derating Analysis for $\mathrm{THD}_{\mathrm{I}}=10 \%$.

\begin{tabular}{|c|c|c|c|}
\hline \multirow[t]{2}{*}{ Operating Conditions } & \multicolumn{2}{|c|}{$\begin{array}{c}\text { Profile Type and } \\
\text { Capacity Limit (p.u.) }\end{array}$} & \multirow[t]{2}{*}{ Derating (\%) } \\
\hline & B & A & \\
\hline Normal Operations & 1.00 & 0.72 & 72.00 \\
\hline Long-term Emergency Loading (Hot-spot temperature limit) & 1.47 & 1.18 & 80.28 \\
\hline Long-term Emergency Loading (Top-oil temperature limit) & 1.46 & 1.20 & 82.19 \\
\hline Short-term Emergency Loading (Hot-spot temperature limit) & 1.67 & 1.43 & 85.63 \\
\hline Short-term Emergency Loading (Top-oil temperature limit) & 1.46 & 1.20 & 82.19 \\
\hline
\end{tabular}

\section{Conclusions}

The increased implementation of DSM applications to control EV charging and ES systems will significantly change the load characteristics of substation power transformers when combined with the effects of PV systems. The load profile will be flatter and possibly possess higher harmonic distortion levels than the historical load profile. The new characteristics will cause excessive heating within the unit, which results in increased aging and risk of permanent damage. If capacity limits were developed utilizing historical load profiles with cyclic characteristics, then the units will experience higher than anticipated temperatures for loads at or above the nameplate ratings.

Harmonic distortion may also contribute to excessive heating, which can result in excessive aging and/or damage. Even at low penetration levels of PV, EV charging, and ES applications, current harmonic distortion can exceed $10 \%$.

To establish new capacity limits that reflect a flatter load profile with a higher harmonic content, the modeling methods described in IEEE Std. C57.91-2011 and Schijndel, Wouters, and Wetzer can be combined to identify the new peak demand limits $[2,10]$. Options for reducing the effects caused by excessive internal heating include derating existing capacity limits for units still in service and possibly augmenting the design of new units by reducing their losses and increasing their solid dielectric characteristics.

Author Contributions: K.D.M. led the research effort, coordinated the field testing with Xcel Energy, and developed testing parameters. K.D.M. and P.R. developed the thermal model of the 50 MVA SPX unit utilizing Matlab. P.R. also performed the analysis regarding the impact of design variations. J.C. was responsible for quality control of the project and verifying data results. All authors contributed to the development of the manuscript.

Funding: The research was sponsored by California State University, Fresno.

Conflicts of Interest: The authors declare no conflicts of interest.

\section{References}

1. Willis, H.L. Power Distribution Planning Reference Book, Second Edition, Revised and Expanded; Marcel Dekker: New York, NY, USA, 2004; p. 404.

2. IEEE Standard C57.91-2011. IEEE Guide for Loading Mineral-oil Immersed Transformers; IEEE: Piscataway, NJ, USA, 2012.

3. Electric Power Research Institute. The Integrated Grid: Realizing the Full Value of Central and Distributed Energy Resources. Available online: http://energy.gov/sites/prod/files/2015/03/f20/EPRI\%20Integrated\% 20Grid021014.pdf (accessed on 8 August 2019).

4. Munson, K. Integrated Energy Storage: An Answer to Addressing the Duck Curve. Available online: http://www.renewableenergyworld.com/articles/2015/04/integrated-energy-storage-an-answer-toaddressing-the-duck-curve.html (accessed on 8 August 2019).

5. California ISO. What the Duck Curve Tells us about Managing a Green Grid. 2014. Available online: https: //www.caiso.com/Documents/FlexibleResourcesHelpRenewables_FastFacts.pdf (accessed on 8 August 2019). 
6. McBee, K.D. Transformer aging due to high penetrations of PV, EV, charging, and energy storage. In Proceedings of the 2017 Ninth Annual IEEE Green Technologies Conference (GreenTech), Denver, CO, USA, 29-31 March 2016.

7. Staats, P.; Grady, W.; Arapostanthis, A.; Thallam, R. A procedure for derating a substation transformer in the presence of widespread electric vehicle battery charging. IEEE Trans. Power Deliv. 1997, 12, 1562-1568. [CrossRef]

8. McBee, K.D.; Simões, M.G. General smart meter guidelines to accurately assess the aging of distribution transformers. IEEE Trans. Smart Grid 2015, 16, 2967-2979. [CrossRef]

9. Das, B.; Radakovic, Z. Is transformer kVA derating always required under harmonics? A manufacturer's perspective. IEEE Trans. Power Deliv. 2018, 33, 2693-2699. [CrossRef]

10. Schijndel, A.; Wouters, P.; Wetzer, J. Modeling of replacement alternatives for power transformer populations. IEEE Trans. Power Deliv. 2012, 27, 506-513. [CrossRef]

11. Schijndel, A.; Wetzer, J.; Wouters, P. Remaining lifetime modelling for replacement of power transformer populations. In Proceedings of the 2008 International Conference on Condition Monitoring and Diagnosis, Beijing, China, 21-24 April 2008.

12. Duarte, E.; Miller, D.; Lawrence, M.; Prout, P.; Gavin, J.; Falla, D.; McGrail, T. Prioritizing transformers for condition based asset replacement. In Proceedings of the IEEE PES General Meeting, Providence, RI, USA, 25-29 July 2010.

13. IEEE Standard C57.110-2008. IEEE Recommendation Practice for Establishing Liquid-Filled and Dry-Type and Distribution Transformer Capability when Supplying Nonsinusoidal Load Currents; IEEE: Piscataway, NJ, USA, 2008.

14. Faiz, J.; Ghazizadeh, M.; Oraee, H. Derating of transformers under non-linear load current and non-sinuousoidal voltage an overview. IET Electr. Power Appl. 2015, 9, 486-495. [CrossRef]

15. IEEE Standard 519-2014. Recommended Practices and Requirements for Harmonic Control in Electric Power Systems; IEEE: New York, NY, USA, 1992.

16. McBee, K.D.; Simões, M.G. Evaluating the long-term impact of continuously increasing harmonic demand on feeder-level voltage distortion. IEEE Trans. Ind. Appl. 2014, 50, 2142-2149. [CrossRef]

17. McBee, K.D.; Simões, M.G. Locating the origin of feeder level harmonics utilizing remote THD measurements. In Proceedings of the 2011 IEEE Industrial Applications Society Annual Meeting, Orlando, FL, USA, 9-13 October 2011.

18. Munir, S.; Li, Y.W. Residential distribution system harmonic compensation using PV interfacing inverter. IEEE Trans. Smart Grid 2013, 4, 816-827. [CrossRef]

19. Vasudevarao, B.; Stifter, M.; Zehetbauer, P. Methodology for creating composite standard load profiles based on real load profile analysis. In Proceedings of the 2016 IEEE PES Innovative Smart Grid Technologies Conference Europe (ISGT-Europe), Ljubljana, Slovenia, 9-12 October 2016.

20. Fezai, S.; Belhadj, J. Load profile impact on stand-alone photovoltaic system. In Proceedings of the 2016 7th International Renewable Energy Congress (IREC), Hammamet, Tunisia, 22-24 March 2016.

21. Macdonald-Smith, A. Energy storage tipped to drive revolution in power grids. Available online: http://www.smh.com.au/business/energy/energy-storage-tipped-to-drive-revolution-in-powergrids-20151005-gk1ypb.html (accessed on 8 August 2019).

22. Mamen, A.; Supatti, U. A survey of hybrid energy storage systems applied for intermittent renewable energy systems. In Proceedings of the 2017 14th International Conference on Electrical Engineering/Electronics, Computer, Telecommunications and Information Technology (ECTI-CON), Phuket, Thailand, 27-30 June 2017.

23. di Piazza, M.; Luna, M.; la Tona, G.; di Piazza, A. Energy management of hybrid PV-storage systems for improved grid integration. In Proceedings of the 2017 IEEE International Conference on Environment and Electrical Engineering and 2017 IEEE Industrial and Commercial Power Systems Europe (EEEIC/I\&CPS Europe), Milan, Italy, 6-9 June 2017.

24. Choi, S.; Sin, M.; Kim, D.; Won, C.; Jung, Y. Versatile power transfer strategies of PV-battery hybrid system for residential use with energy management system. In Proceedings of the 2014 International Power Electronics Conference (IPEC-Hiroshima 2014_ECCE ASIA), Hiroshima, Japan, 18-21 May 2014. 
25. Shrestha, S.; Hansen, T. Distribution feeder impacts of electric vehicles charging in an integrated traffic and power network. In Proceedings of the 2016 North American Power Symposium (NAPS), Denver, CO, USA, 18-20 September 2016.

26. Rezaee, S.; Farjah, E.; Khorramdel, B. Probabilistic analysis of plug-in electric vehicles impact on electric grid through homes and parking lots. IEEE Trans. Sustain. Energy 2013, 4, 1024-1033. [CrossRef]

27. Department of Energy. Grid Energy Storage. Available online: http://energy.gov/sites/prod/files/2014/09/f18/ Grid\%20Energy\%20Storage\%20December\%202013.pdf (accessed on 8 August 2019).

28. Liu, C.C.; McArthur, S.; Lee, S. Smart Grid Handbook; Wiley: West Sussex, UK, 2016; Volume 1, p. 133.

29. Jozi, F.; Mazlumi, K.; Hosseini, H. Charging and discharging coordination of electric vehicles in a parking lot considering the limitation of power exchange with the distribution system. In Proceedings of the 2017 IEEE 4th International Conference on Knowledge-Based Engineering and Innovation (KBEI), Tehran, Iran, 22 December 2017.

30. Ghalebani, A.; Das, T. Design of financial incentive programs to promote net zero energy buildings. IEEE Trans. Power Sys. 2017, 32, 75-84. [CrossRef]

31. Koutra, S.; Brenet, A.; Becue, V.; Ioakimidis, C. From the smart ground to smart grid: A method to achieve multi-energy system. In Proceedings of the 2016 IEEE International Energy Conference (ENERGYCON), Leuven, Belgium, 4-8 April 2016.

32. Kumar, S. Towards net zero energy solar building, system, and concepts. In Proceedings of the 2016 First International Conference on Sustainable Green Buildings and Communities (SGBC), Chennai, India, 18-20 December 2016.

33. Nour, M.; Ramadan, H.; Ali, A.; Farkas, C. Impacts of plug-in electric vehicles charging on low voltage distribution networks. In Proceedings of the 2018 International Conference on Innovative Trends in Computer Engineering (ITCE), Aswan, Egypt, 19-21 February 2018.

34. Nour, M.; Said, S.; Ali, A.; Farkas, C. Smart charging of electric vehicles according to electricity price. In Proceedings of the 2019 International Conference on Innovative Trends in Computer Engineering (ITCE'2019), Aswan, Egypt, 2-4 February 2019.

35. Cazavu, E.; Petrescu, L. Derating the three-phase power distribution transformers under unonsinusoidal operating conditions: A case study. In Proceedings of the 2014 16th International Conference on Harmonics and Quality of Power (ICHQP), Bucharest, Romania, 25-28 May 2014.

36. Shareghi, M.; Phung, B.; Naderi, M.; Blackburn, T.; Ambikairajah, E. Effects of current and voltage harmonics on distribution transformer losses. In Proceedings of the 2012 IEEE International Conference on Condition Monitoring and Diagnosis, Bali, Indonesia, 23-27 September 2012.

37. Cazacu, E.; Petrescu, L.; Ionita, V. Losses and temperature rise within power transformers subjected to distorted currents. In Proceedings of the 2017 15th International Conference on Electrical Machines, Drives and Power Systems (ELMA), Sofia, Bulgaria, 1-3 June 2017.

38. Deokar, S.; Waghmare, L. Impact of power harmonics on insulation failure of distribution transformer and its remedial measures. In Proceedings of the 2011 3rd International Conference on Electronics Computer Technology, Kanyakumari, India, 8-10 April 2011.

39. Cazavu, E.; Petrescu, L.; Lonita, V. Derating of power distribution transformers serving nonlinear industrial loads. In Proceedings of the 2017 International Conference on Optimization of Electrical and Electronic Equipment (OPTIM) \& 2017 Intl Aegean Conference on Electrical Machines and Power Electronics (ACEMP), Brasov, Romania, 25-27 May 2017.

40. Kelley, A.; Edwards, S.; Rhode, J.; Baran, M. Transformer derating for harmonic currents: A wide-band measurement approach for energized transformers. IEEE Trans. Ind. Appl. 1999, 35, 1450-1457. [CrossRef]

41. Sharifian, M.; Faiz, J.; Fakheri, S.; Zraatparvar, A. Derating of distribution transformers for non-sinusoidal load currents using finite element method. In Proceedings of the 10th IEEE International Conference on Electronics, Circuits and Systems, Sharjah, UAE, 14-17 December 2003.

42. Masoum, M.; Moses, P.; Masourm, A. Derating of asymmetric three-phase transformers serving unbalanced nonlinear loads. IEEE Trans. Power Deliv. 2008, 23, 2033-2041. [CrossRef]

43. de Brito, B.; van Rhyn, P.; Pretorius, J. The use of power quality standards to establish an equivalent transformer capability under harmonic loading. In Proceedings of the 2016 IEEE International Conference on Power System Technology (POWERCON), Wollongong, Australia, 28 September-1 October 2016. 
44. IEC 60969:2016 RLV. Self-Ballasted Compact Fluorescent Lamps for General Lighting Services-Performance Requirements; IEC: Geneva, Switzerland, 2017.

45. IEEE Standard. 1547.2-2018-IEEE Standard for Interconnection and Interoperability of Distributed Energy Resources with Associated Electric Power Interfaces; IEEE: New York, NY, USA, 2018.

46. Ranga, C.; Chandel, A.; Chandel, R. Performance analysis of cellulose and nomex-910 impregnated oil filled power transformers. Int. J. Electr. Eng. Inform. 2017, 9, 394-406. [CrossRef]

47. Zhang, X.; Ren, L.; Yu, J.; Xu, Y.; Lei, Q.; Li, X.; Han, B. Dual-temperature evaluation of a high-temperature insulation system for liquid-immersed transformer. Energies 2018, 11, 1957. [CrossRef]

48. Ranga, C.; Chandel, A. Life assessment of TUK and Nomex-910 imprenated mineral transformer oils using raman spectroscopy. In Proceedings of the 2017 3rd International Conference on Condition Assessment Techniques in Electrical Systems (CATCON), Rupnagar, India, 16-18 November 2017.

49. Marek, R. High-temperature transformers: History, standards and applications. In Proceedings of the 5th Advanced Research Workshop on Transformers, Cordova, Spain, 3-5 October 2016.

50. Ranga, C.; Chandel, A.; Chandel, R. Performance analysis of alternative solid dielectrics of power transformers with a blend of mineral and silicon oils. IETE Tech. Rev. 2018, 35, 331-341.

(C) 2019 by the authors. Licensee MDPI, Basel, Switzerland. This article is an open access article distributed under the terms and conditions of the Creative Commons Attribution (CC BY) license (http://creativecommons.org/licenses/by/4.0/). 